\title{
Effect of Urea on Synthesis of Ceramics Materials by the Modified Combustion Method
}

\author{
D. Cruz ${ }^{a, *}$, H.B. Ortíz-Oliveros ${ }^{b}$, A. Rivera Zepeda ${ }^{a}$, G. Rosano-Ortega $^{c}$ \\ AND N. TEPALE $\mathrm{OCHOA}^{a}$
}

${ }^{a}$ Facultad de Ingeniería Química, Benemérita Universidad Autónoma de Puebla, C.P. 72570, Puebla, Pue., México

${ }^{b}$ Instituto Nacional de Investigaciones Nucleares, Dirección de Investigación Tecnológica,

C.P. 18-1027, 11801 México, DF, México

${ }^{c}$ Research Department, Universidad Popular Autónoma del Estado de Puebla (UPAEP), Puebla, México

(Received February 19, 2015; in final form June 23, 2015)

The proportion of urea in the modified combustion method to prepare lithium metasilicate $\left(\mathrm{Li}_{2} \mathrm{SiO}_{3}\right)$ powders was investigated. Reactions were performed using $\mathrm{LiOH}: \mathrm{H}_{2} \mathrm{SiO}_{3}: \mathrm{CH}_{4} \mathrm{~N}_{2} \mathrm{O}$ in molar ratios of 1:1:1, 1:1:2, 1:1:3, 1:1:4 and 1:1:5 which were heated at $450{ }^{\circ} \mathrm{C}$ during 5 min. It was found, by X-ray diffraction, that $\mathrm{LiOH}: \mathrm{H}_{2} \mathrm{SiO}_{3}: \mathrm{CH}_{4} \mathrm{~N}_{2} \mathrm{O}$ in the ratio of $1: 1: 3$ was the more adequate molar ratio to produce mainly $\mathrm{Li}_{2} \mathrm{SiO}_{3}$. It was observed that excess of urea produced mainly silicium dioxide $\left(\mathrm{SiO}_{2}\right)$ in coesite phase instead $\mathrm{Li}_{2} \mathrm{SiO}_{3}$. Thermogravimetric analyses showed that decomposition products of urea, such as biuret, cyanic acid and cyanuric acid, were found in samples prepared with high proportions of urea (1:1:4 and 1:1:5). Carbonates identified by IR spectroscopy were found in samples prepared with $\mathrm{LiOH}: \mathrm{H}_{2} \mathrm{SiO}_{3}: \mathrm{CH}_{4} \mathrm{~N}_{2} \mathrm{O}$ in 1:1:1, 1:1:2, 1:1:3, 1:1:14 and 1:1:5 molar ratios.

DOI: $10.12693 /$ APhysPolA.128.336

PACS: 64.70.ph, 28.41.Bm, 88.20.jj

\section{Introduction}

Lithium ceramics such as $\mathrm{Li}_{2} \mathrm{O}, \mathrm{Li}_{2} \mathrm{SiO}_{3}, \mathrm{Li}_{4} \mathrm{SiO}_{4}$, $\mathrm{Li}_{2} \mathrm{TiO}_{3}, \mathrm{LiAlO}_{2}$ and $\mathrm{Li}_{2} \mathrm{ZrO}_{3}$ attract attention as candidates for tritium breeding material in $\mathrm{D}-\mathrm{T}$ fusion reactors [1-3]. Lithium metasilicate $\left(\mathrm{Li}_{2} \mathrm{SiO}_{3}\right)$ is known to have good tritium solubility [4-6], thermophysical, chemical and mechanical stability at high temperatures. Several methods such as sol-gel, precipitation and solid state have been utilized to prepare lithium ceramics, however recently new methods have been developed to prepare ceramic powders, like combustion syntheses.

Combustion method, which is a solid-state process based on the principle of explosive decomposition of a metal nitrate and fuels mixtures, is a quick and straightforward method to produce ceramic powders [7-9] that, in general, takes less than 5 min. In previous studies $[2,10]$ lithium silicates were prepared using a modified combustion method; heat required to maintain the reaction was supplied from the reaction itself and not from an external source. This method requires $\mathrm{LiOH}, \mathrm{H}_{2} \mathrm{SiO}_{3}$ and urea as fuel, and the combustion takes place in the presence of air to obtain the oxygen needed for the ignition. The purpose of the present paper is to further study this method and to analyze the obtained ceramics by thermal methods.

\section{Experimental methods}

Silicic acid $\left(\mathrm{H}_{2} \mathrm{SiO}_{3}-\right.$ molecular weight $=$ $\left.78.086 \mathrm{~g} \mathrm{~mol}^{-1}\right)$, lithium hydroxide $(\mathrm{LiOH}-$ molecular

\footnotetext{
*corresponding author; e-mail: daniel.cruz@correo.buap.mx
}

weight $\left.=23.950 \mathrm{~g} \mathrm{~mol}^{-1}\right)$ and urea $\left(\mathrm{CH}_{4} \mathrm{~N}_{2} \mathrm{O}\right.$ molecular weight $\left.=60.060 \mathrm{~g} \mathrm{~mol}^{-1}\right)$ were obtained from Mallinckrodt and Merck. These three substances were mixed with distilled water and heated until most of water was evaporated. The mixture was then transferred into a high temperature muffle furnace Barnstead Thermolyne Corporation maintained at $450^{\circ} \mathrm{C}$ where the combustion reaction was completed within 5 min. Preparation procedure of lithium silicates by the modified combustion method is demonstrated in the flow sheet below.

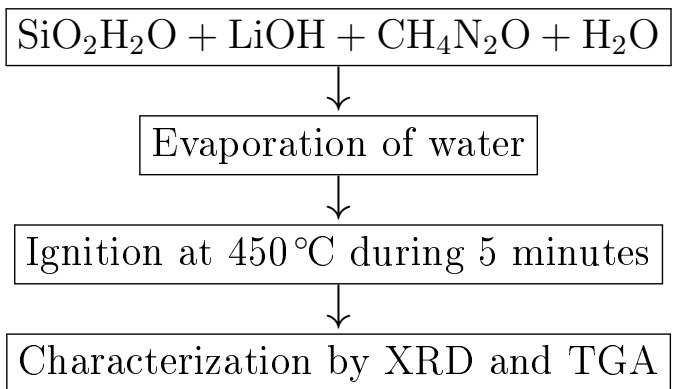

Five mixtures were made using $\mathrm{LiOH}: \mathrm{H}_{2} \mathrm{SiO}_{3}: \mathrm{CH}_{4} \mathrm{~N}_{2} \mathrm{O}$ at different molar ratios and were labeled as 1:1:1, 1:1:2, 1:1:3, 1:1:4, and 1:1:5; i.e., sample 1:1:3 corresponds to the sample prepared with $\mathrm{LiOH}, \mathrm{H}_{2} \mathrm{SiO}_{3}$ and $\mathrm{CH}_{4} \mathrm{~N}_{2} \mathrm{O}$ at a molar ratio of 1:1:3.

\subsection{Samples characterization}

X-ray diffraction (XRD) was measured with a Siemens D-500 diffractometer coupled to a copper anode X-ray tube. Lithium silicates were identified by the corresponding JCPDS (Joint Committee on Powder Diffraction Standards) and the relative content of silicates and 
amorphous part was estimated from the areas under the diffraction peaks $[11,12]$. Functional groups of the powders in the infrared region were analyzed in a MagnaIR Spectrometer 550 Nicolet. Samples were mixed with potassium bromide to form tablets. Thermogravimetric analysis (TGA) was performed to analyze the behavior of the synthesized powders (TGA 51, Thermogravimetric Analyzer, T.A. Instruments). The samples (15 mg) were studied at a heating rate of $10^{\circ} \mathrm{C} \mathrm{min}^{-1}$ up to $1000^{\circ} \mathrm{C}$ in

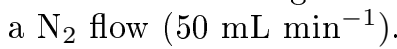

\section{Results and discussion}

\subsection{X-ray diffraction analysis}

$\mathrm{Li}$ et al. have reported that one of the major parameters that determines the phase formation of the synthesized powder is the ratio of fuel to metal nitrate in the combustion reaction. In the present work, the effects of the ratio of fuel to metal oxides were investigated in a precursor solution consisting of urea as a fuel and a mixed lithium hydroxide and silicon oxide [8]. XRD patterns, in Fig. 1, show the diffractograms of samples 1:1:1, 1:1:2, $1: 1: 3,1: 1: 4$, and $1: 1: 5$.

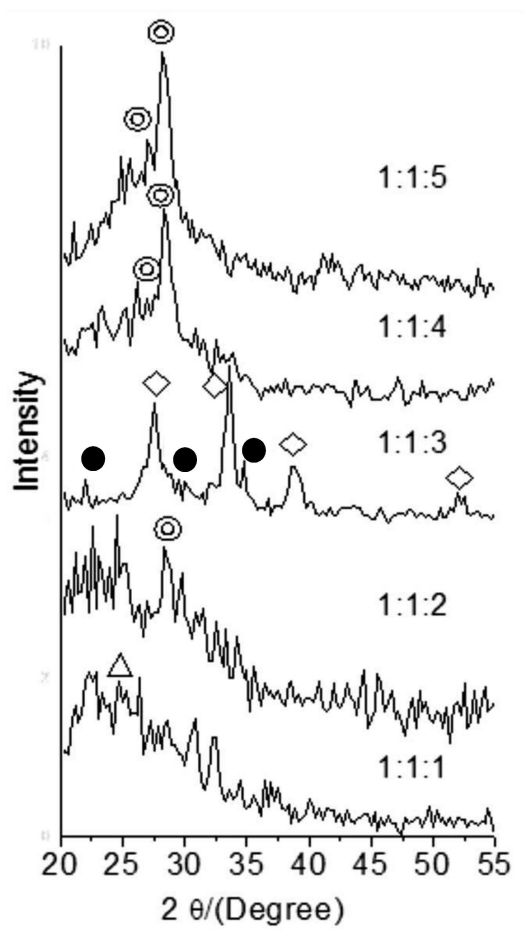

Fig. 1. XRD patterns of lithium silicate samples prepared by the modified combustion method. LiOH: $\mathrm{H}_{2} \mathrm{SiO}_{3}: \mathrm{CH}_{4} \mathrm{~N}_{2} \mathrm{O}$ molar ratios 1:1:1, 1:1:2, 1:1:3, 1:1:4 and 1:1:5. $\diamond=\mathrm{Li}_{2} \mathrm{SiO}_{3}(\mathrm{JCPDS}: 29-828) \odot=\mathrm{SiO}_{2}$ (JCPDS : 29-85) $\bullet=\mathrm{Li}_{4} \mathrm{SiO}_{4}$ (JCPDS: 17-197).

For low urea molar ratios (samples 1:1:1 and 1:1:2), mainly, amorphous material was obtained. On the other hand, for high urea molar ratios (samples 1:1:4 and 1:1:5) the amorphous material was present as well, however there was found the presence of considerable amounts of silicon dioxide $\left(\mathrm{SiO}_{2}\right)$ in coesite phase. Coesite is formed only to $20 \times 10^{8} \mathrm{~Pa}$ at $450^{\circ} \mathrm{C}$ or higher pressures, while in this work, synthesis was carried out at $450^{\circ} \mathrm{C}$ and 1 atm $[13,14]$. This can be due as a result of the phase transformations starting from the $\mathrm{Li}_{2} \mathrm{O} 2 \mathrm{SiO}_{2}$ glass composition as reported by Buchner and Balzaretti [15], reaction (1):

$$
\mathrm{Li}_{2} \mathrm{O}_{2} \mathrm{SiO}_{2} \text { (glass) } \longrightarrow \mathrm{Li}_{2} \mathrm{Si}_{2} \mathrm{O}_{5}
$$

$$
\longrightarrow \mathrm{Li}_{2} \mathrm{SiO}_{3}+\mathrm{SiO}_{2} \text { (quartz or coesite). }
$$

The segregation of $\mathrm{SiO}_{2}$ should be expected due to the deficient lithium and high urea concentration.

For molar ratio $1: 1: 3$, the formation of $\mathrm{Li}_{2} \mathrm{SiO}_{3}$ as the main lithium silicate crystallized can be observed. It has been well known that there are three types of reaction sequences occurring in the fabrication of glass-ceramics, depending on glass composition [16]. Type I is the simultaneous nucleation of lithium metasilicate and lithium disilicate phases, followed by the transformation of lithium metasilicate to lithium disilicate. In the second type, lithium metasilicate nucleates first and then transforms to lithium disilicate at a higher temperature. Reaction sequence type III is when the lithium disilicate phase directly forms the glass whereas no lithium silicate phase is formed. In this study, it was used a deficient lithium concentration and one calcination temperature of $450{ }^{\circ} \mathrm{C}$ during $5 \mathrm{~min}$, under these conditions the lithium metasilicate begins to nucleate and the transition to lithium disilicate is not favored. On the other hand, the formation of $\mathrm{Li}_{2} \mathrm{SiO}_{3}$ should be thermodynamically favored under high pressure and high temperature; it is known that urea decomposition produces high pressure and high temperature [16].

\subsection{Infrared spectroscopy}

IR spectra are shown in Fig. 2. Sample 1:1:3 corresponds to the powders with major proportion of $\mathrm{Li}_{2} \mathrm{SiO}_{3}$. Nakamoto [17] reported that the $\left[\mathrm{SiO}_{4}^{-4}\right]$ tetrahedral arrangements in silicate structures can be identified by the presence of the following bands: $\nu_{1}, 819 \mathrm{~cm}^{-1}$; $\nu_{3}, 956 \mathrm{~cm}^{-1}$, and $\nu_{4} 527 \mathrm{~cm}^{-1}$, in the present study these bands were found in sample 1:1:3 at 830, 950, and $520 \mathrm{~cm}^{-1}$, respectively.

The bands around 1050,650 , and $1000 \mathrm{~cm}^{-1}$ correspond to $\mathrm{Si}-\mathrm{O}-\mathrm{Si}[17], \mathrm{O}-\mathrm{Si}-\mathrm{O}[17]$ and $\mathrm{Si}-\mathrm{O}$ [18] vibrations, respectively. The band at $750 \mathrm{~cm}^{-1}$ is attributed to O-Li-O structure [17]. Although by XRD no carbonates were observed, by IR spectroscopy the presence of carbonates, probably in the form of $\mathrm{Li}_{2} \mathrm{CO}_{3}$, were observed. The principal bands assigned to carbonate ions are $\nu_{3}$, $1350-1380 \mathrm{~cm}^{-1}$, and $\nu_{2}, 850-880 \mathrm{~cm}^{-1}[17,18]$ and in the present work the bands corresponding to carbonates were observed in all samples.

Nakamoto et al. [17-21] reported that urea structure can be identified by the presence of the following bands: $\nu \mathrm{NH} 3500 \mathrm{~cm}^{-1}, \nu \mathrm{CO} 1730 \mathrm{~cm}^{-1}, \nu \mathrm{CO}+\delta \mathrm{NH} 1630 \mathrm{~cm}^{-1}$ 


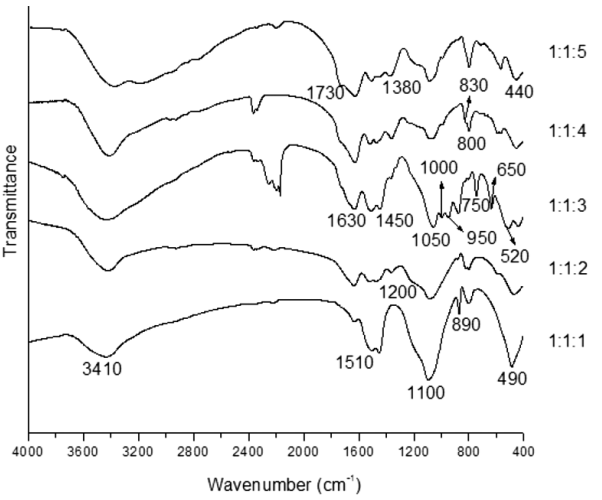

Fig. 2. IR spectra of lithium silicate samples prepared by the modified combustion method. LiOH: $\mathrm{H}_{2} \mathrm{SiO}_{3}: \mathrm{CH}_{4} \mathrm{~N}_{2} \mathrm{O}$ molar ratios 1:1:1, 1:1:2, $1: 1: 3,1: 1: 4$ and $1: 1: 5$.

and $\nu \mathrm{C}-\mathrm{N} 1450 \mathrm{~cm}^{-1}$. In this work, the bands corresponding to residual urea present in the samples were found at around $3410,1730,1630$, and $1450 \mathrm{~cm}^{-1}$ in samples $1: 1: 3,1: 1: 4$ and 1:1:5, which were prepared with high urea proportions.

\subsection{Thermogravimetric analysis}

The TGA analyses of samples 1:1:1, 1:1:2, 1:1:3, 1:1:4 and 1:1:5 are given in Fig. 3 and the weight losses found are displayed in Table.

TABLE

Weight loss for samples $1: 1: 1$ to $1: 1: 5$ prepared by the modified combustion method.

\begin{tabular}{c|c|c|c|c|c|c}
\hline \hline \multirow{2}{*}{$\begin{array}{c}\text { LiOH: } \\
\text { molar ratio }\end{array} \mathrm{SiO}_{3}: \mathrm{CH}_{4} \mathrm{~N}_{2} \mathrm{O}$} & \multicolumn{5}{|c}{ Temperature range [ $\left.{ }^{\circ} \mathrm{C}\right]$} \\
\cline { 2 - 6 } & $250-480$ & $480-600$ & $300-400$ & $420-500$ & $560-600$ \\
\cline { 2 - 6 } Weight loss [\%] \\
$1: 1: 1$ & 3.5 & 6.5 & 0 & 0 & 0 \\
$1: 1: 2$ & 3 & 4.5 & 0 & 0 & 0 \\
$1: 1: 3$ & 3.2 & 6.8 & 0 & 0 & 0 \\
$1: 1: 4$ & 0 & 0 & 7 & 14 & 9 \\
$1: 1: 5$ & 0 & 0 & 10 & 27 & 20
\end{tabular}

Samples 1:1:1 to 1:1:3 showed two main weight losses, one from $250{ }^{\circ} \mathrm{C}$ to $480^{\circ} \mathrm{C}$ and the second from $480^{\circ} \mathrm{C}$ to $600^{\circ} \mathrm{C}$ (Table). The first weight loss can be attributed to the dehydroxylation process of the residual $\mathrm{LiOH}$ in the samples and the second, between 480 and $600^{\circ} \mathrm{C}$, may be attributed to the decarbonation of the samples; as we have already seen the presence of $\mathrm{CO}_{3}^{-2}$ ions by IR analyses on samples prepared with low urea proportions.

These weight loss can be explained considering that for low fuel proportion (samples 1:1:1 to 1:1:3) during the preparation of the samples urea reacts with the oxygen present in air forming, preferentially, lithium carbonate as shown in reaction (2):

$$
2 \mathrm{LiOH}+2 \mathrm{H}_{2} \mathrm{NCNH}_{2}+3 \mathrm{O}_{2} \longrightarrow \mathrm{Li}_{2} \mathrm{CO}_{3}+5 \mathrm{H}_{2} \mathrm{O}+\mathrm{C} \mathrm{O}_{2}+2 \mathrm{~N}_{2} \text {. }
$$

The TGA curves of samples prepared with high urea proportion (1:1:4 and 1:1:5) presented three main weight losses: first between $300-400{ }^{\circ} \mathrm{C}$, second between

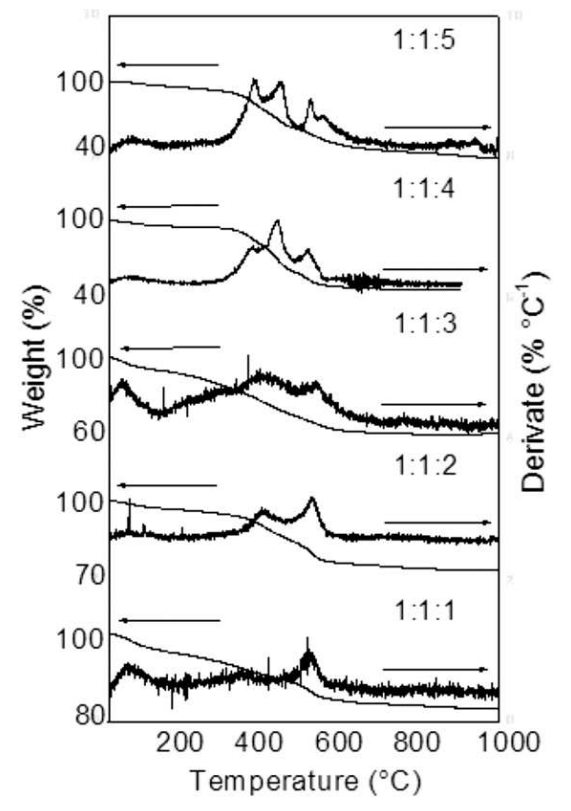

Fig. 3. TGA curves of lithium silicate samples prepared by the modified combustion method. LiOH: $\mathrm{H}_{2} \mathrm{SiO}_{3}: \mathrm{CH}_{4} \mathrm{~N}_{2} \mathrm{O}$ molar ratios 1:1:1, 1:1:2, $1: 1: 3,1: 1: 4$ and $1: 1: 5$.

$420-500^{\circ} \mathrm{C}$, and third between $560-600^{\circ} \mathrm{C}$. The first weight loss for samples 1:1:4 and 1:1:5 can be attributed, as suggested by Wynne [22], to the decomposition of urea in the absence of oxygen mainly into biuret, the second weight loss to the decomposition of biuret into cyanic acid and finally, the third weight loss, to the decomposition of biuret into cyanuric acid as it is shown in reactions $(3)-(6)$ :

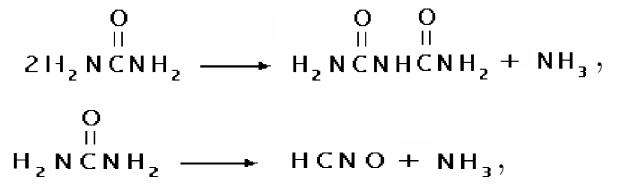

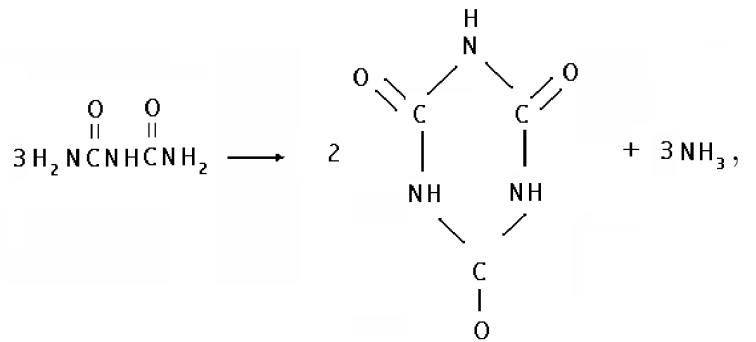

$$
\begin{aligned}
& \text { O } \mathrm{O} \\
& \mathrm{H}_{2} \mathrm{NCNHCNH} \longrightarrow 2 \mathrm{HCNO}+\mathrm{NH}_{3} \text {, }
\end{aligned}
$$

According to the literature [7, 9], the proportion of fuel in the precursors affects the ignition temperature during the combustion process, which can be as high as $1750^{\circ} \mathrm{C}$ [7]. Although urea decomposes completely in the temperature range at about $480^{\circ} \mathrm{C}[22]$, it is evident from IR and TGA analyses that urea residues are present in the samples prepared in the present work, mainly in those prepared with high urea proportions, which proba- 
bly can be due to the synthesis time not being enough [7] to allow the complete decomposition of urea to $\mathrm{CO}_{2}, \mathrm{~N}_{2}$ and $\mathrm{H}_{2} \mathrm{O}$.

\section{Conclusions}

In this study, $\mathrm{Li}_{2} \mathrm{SiO}_{3}$ was synthesized using a modified combustion method. Oxygen present in air was used during the combustion process. It was found by XRD that $\mathrm{LiOH}: \mathrm{H}_{2} \mathrm{SiO}_{3}: \mathrm{CH}_{4} \mathrm{~N}_{2} \mathrm{O}$ molar ratio 1:1:3 formed $\mathrm{Li}_{2} \mathrm{SiO}_{3}$ as the main lithium metasilicate crystallized. Excess of urea did not allow the formation of lithium metasilicate and formed mainly amorphous material and coesite $\left(\mathrm{SiO}_{2}\right)$. This experimental result shows that the ratio of fuel to lithium hydroxide and silicon oxide is important in obtaining the crystalline $\mathrm{Li}_{2} \mathrm{SiO}_{3}$ powder by combustion reaction.

Carbonates, as observed by IR spectroscopy, were present in all samples. By IR spectroscopy there was confirmed the presence of $\mathrm{Li}_{2} \mathrm{SiO}_{3}$. TGA analyses showed that samples 1:1:1 to $1: 1: 3$ prepared with low proportion of urea presented weight loss due to dehydroxylation and decarbonation processes. However, samples prepared with high proportion of urea, 1:1:4 and 1:1:5, presented weight lost mainly because of the decomposition of urea; probably into biuret, cianuric acid, and cyanic acid.

\section{Acknowledgments}

We thank M. Espinosa for the XRD measurements and E. Morales and C. Rodriguez for the IR and TGA analyses. D. Cruz acknowledged CONACYT, México for financial support.

\section{References}

[1] C.H. Jung, J.Y. Park, S.J. Oh, H.K. Park, Y.S. Kim, D.K. Kim, J.H. Kim, J. Nucl. Mater. 253, 203 (1998).

[2] D. Cruz, S. Bulbulian, J. Nucl. Mater. 312, 262 (2003).

[3] N. Roux, C. Johnson, K. Noda, J. Nucl. Mater. A 191-194, 15 (1992).
[4] Yangsheng Zhang, G.C. Stangle, J. Mater. Res. 9, 1997 (1994).

[5] L. Montanaro, J.P. Lecompte, J. Mater. Sci. 27, 3763 (1992).

[6] C.E. Johnson, K. Noda, N. Roux, J. Nucl. Mater. 258-263, 140 (1998).

[7] J.J. Kingsley, L.R. Pederson, Mater. Lett. 18, 89 (1993).

[8] Fei Li, Keao Hu, Jianlin Li, Dong Zhang, Gang Chen, J. Nucl. Mater. 300, 82 (2002).

[9] L.A. Chick, L.R. Pederson, G.D. Maupin, J.L. Bates, L.E. Thomas, G.J. Exarhos, Mater. Lett. 10, 6 (1990).

[10] D. Cruz, Ph.D. Thesis, Autonomous University of the State of Mexico, Toluca, México, 2006.

[11] J. Jimenez-Becerril, P. Bosch, S. Bulbulian, J. Nucl. Mater. 185, 304 (1991).

[12] H.P. Klug, L.E. Alexander, X-Ray Diffraction Procedures: For Polycrystalline and Amorphous Materials, 2nd ed., John Wiley \& Sons, New York 1974, p. 960.

[13] M. Akaogi, H. Yusa, K. Shiraishi, T. Suzuki, J. Geophys. Res. Solid Earth 100, 22337 (1995).

[14] P.W. Mirwald, H.J. Massonne, J. Geophys. Res. 85, 6983 (1980)

[15] S. Buchner, N.M. Balzaretti, J. Phys. Chem. Solids 74, 1179 (2013).

[16] S. Huang, Z. Huang, W. Gao, P. Cao, Sci. Rep. 5 9159 (2015)

[17] K. Nakamoto, Infrared and Raman Spectra of Inorganic and Coordination Compounds, 4th ed., Part III, Coordination Compounds, Wiley, New York 1986, p. 268.

[18] R.T. Conley, J. Calderón, J. Avendaño, Infrared Spectroscopy, 1st ed., Alhambra, Madrid 1979.

[19] G. Socrates, Infrared Characteristic Group Frequencies, Tables and Charts, 2nd ed., Wiley, New York 1995, p. 188.

[20] C.J. Pouchert, The Aldrich Library of Infrared Spectra, 2nd ed., Vol. 3, Aldrich Chemical, Milwaukee, Wisconsin 1997, p. 799.

[21] M. Avram, G.H.D. Mateescu, Infrared Spectroscopy: Applications in Organic Chemistry, Krieger Pub., USA 1972

[22] A.M. Wynne, J. Chem. Educ. 64, 180 (1987). 